\title{
Cult of the Dead Cow by Menn, June 2019: a fundamental misunderstanding.
}

Camille Akmut

June 14, 2019

\begin{abstract}
Beginning or end of a culture? The old model of the journalist-turnedhistorian by default. - a book review.
\end{abstract}




\section{Introduction : isomorphic structures}

"I have not slept with any of my subjects."

If such were a condition to be a journalist or documentary filmmaker of technology today, as it is commonly understood to be the rule amongst political reporters, for obvious reasons, their fates would be settled faster than they had settled Applebaum's own.

It is hard to observe the doings of this peculiar circle from afar without being reminded of their predecessors, who were the rock bands of the 1960s, 1970s, 1980s and 1990s, and their groupies (e.g. journalist Annik Honore and Ian Curtis).

In the 2000s, they emerged, and replaced them; all of their habits and ways included, almost identical.

We will forgo any longer discussions or descriptions of this incestuous crowd, of "crypto-anarchists" and "cyber-libertarians" with doubtful understanding of political theory, or history, "theoretical physicists" who conduct their own trials by fire, as churchmen had done in the Middle Ages of queers; and the rest of side characters, who too often land on their backs.

The bottom is nearly bottomless with them, and they know their mutual orifices a little too well for their own good.

Their courtship scenes are like those that could be observed, not without embarrassment by some, in the gymnasiums of ancient Athens in the middle of summer, June;

the remains of which we find now in various comedy plays.

\section{Cult of the Dead Cow : beginning or end of a (hacker) culture?}

Menn must be praised for doing the work that historians do not do, do not understand to be theirs, largely owing to not being able to undertake it, and not least to living in the 21st century as their own predecessors had in the 12 th...

They are too busy with diplomats and the 17th century, the 'Great War', sorcery in the Middle ages, the Habsburgs, and god knows whatever else their feeble minds allowed them to think, and construct as history; adding to a great pile of useless monographs that are thrown away by the ton (we know because we saw it done when libraries close or move).

Menn, on the other hand, has done the world a favor by dedicating his energies to researching, and highlighting one of the great issues and causes of his times, which are ours, and we cannot escape :

"Electronic surveillance, cyberwarfare, artificial intelligence, and manipulated social media are on the brink of pushing societies beyond a point of no return. Even those of us who saw this coming did not think it would get this dire this fast, and definitely not in this way." 1

\footnotetext{
${ }^{1}$ Introduction.
} 
We have proposed the following typology :

- The computer-scientist-turned-historian, by default.

- The journalist-turned-historian, by default.

- The newer model of the historian or social scientist.

The fundamental mistakes of Menn are that he does not appear to have an understanding of the larger picture that is the larger history of his subject.

Neither does he appear to have read his colleague Steven Levy, whose book Hackers, despite few but important faults, has made a tremendous contribution to our current understanding of hacker culture.

Far away from lasting fearful imageries, Levy had turned to the very origins of this culture, establishing its beginnings in the 1960s in various educational institutions.

A hacker was originally a mathematician, computer scientist, electrical engineer, physicist... ${ }^{2}$

They had understood their new discipline and objects so well, they were able to go beyond their respective tenets, rules and laws : creating, and subverting the technology of their days.

We all owe a great debt to Levy :

His descriptions of MIT in the 1960s, its various clubs and laboratories, "the true hackers", the hackers "in the original sense", hacking conceived as clever solutions, to mathematical or computing problems alike; our vision of this important history, this we owe to him.

The newer, negative meanings attached to the word "hacker", and by extension the doings of hackers ie. hacking, have been imposed on them, and us, by others : the mainstream media particularly.

And, yet, some of them, including the subjects of this book, have reveled in this and comforted it.

To help distinguish between the two, the term 'cracker' has been proposed, to cover the newer variants.

It is unclear where the Cult of the Dead Cow stands, and if is a continuation of the original culture or not. Most likely, this nebulous group's identity and members reside somewhere between the two.

While figures such as Laird Brown, as Ronald Deibert portrays him, seem to take much from this original culture;

"Some of our early interactions around hacktivism definitely were important to me in terms of setting up Citizen Lab," Deibert said. "I was, like Laird, inspired by this hacking in the original sense of the word, combined with some political orientation or morality underneath it. I thought that was very appealing. I think we have the same outlook and philosophy about whats acceptable and not." ${ }^{3}$

With others it's less clear (see chapter 11 in particular).

\footnotetext{
${ }^{2}$ Though not only, in our first work we had highlighted how a non-negligible number of leading computer scientists, winners of the Turing Award, came from the humanities and social sciences.

${ }^{3}$ Chapter 9 .
} 
The book suffers from the same problems as all those published by journalists-turned-historians, already pointed out : a general refusal to submit to a proper system of source verification, be it in foot- or end notes. The reader is left to put the pieces together.

So for example when he writes :

"Wherever the attention was, it seemed Jake was there too, even as coauthor of a research paper showing that one could recover plain-text passwords by suddenly freezing a computers RAM data storage." 4

It is not the role of a reader, including reviewer, to fill in the blanks ${ }^{5}$.

\section{Chapter 9 : Tor}

The highlight of this book, we hesitate to say "no doubt", and so we will say for us, is chapter 9 where the origins of Tor, outside of Defense research (specifically US Navy), are explained.

In chapter 10, "Jake", a portrait of Jacob Applebaum is given :

"The apparent answer to Tor's public-relations problem arrived in the person of Jacob Appelbaum (...). Jake was young and good-looking, an engaging public speaker and a frequent presenter at serious security conferences. He also had an extraordinarily compelling personal story. If many hackers turned to computers early to escape hard childhoods, Jakes case was extreme. His mother, a schizophrenic, raised him until she lost custody to an aunt, who left Jake in a group home. He went to his father at age ten, but the man grew addicted to heroin. Father and son lived on buses and in drug dens, and Jake once found his dad overdosing and near death. Returning to group homes, Jake dropped out of high school and taught himself to code, working for the likes of Greenpeace and the Rainforest Action Network. Jake met Tor leaders Roger Dingledine and Nick Mathewson at a Def Con and began volunteering. He joined as staff in 2008 and quickly became Tor's most visible spokesman."

This peculiar circle, as we had called it, creates its heroes as fast as it burns them :

For some, a trial where jury and judges are the same were enough. Meanwhile others' actual pending cases are hand-waved.

We conclude this review with an opinion :

In its needed, but desperate attempts at re-branding, the Tor Project seems to be falling from one trap into the next.

It should not become an offshoot of any one organization - no matter which one.

${ }^{4}$ Chapter 10

${ }^{5}$ Halderman et al.. 2008. "Lest We Remember: Cold Boot Attacks on Encryption Keys". 
And, should not become its revolving door, any more than it already is, or has become.

It is too important.

Not only do non-profit's have profits, they have interests too. ${ }^{6}$

${ }^{6}$ Fred von Lohmann went from working for the EFF, and Tor, where he sat on the Board of Directors, to Google... 


\section{References}

—. 2018 [2017]. "Social conditions of outstanding contributions to computer science : a prosopography of Turing Award laureates (1966-2016)."

—. 2019. "Hackers Revisited : the "original "hackers"". Clever solutions, political acts."

—. 2019. "The Libertarian roots of the EFF."

https://2019.www.torproject.org/about/contributors.html.en 